\title{
"Why Should I Study English If I'm Never Going to Leave This Town?" Developing Alternative Orientations to Culture in the EFL Classroom through CAR
}

\section{Luis S. Villacañas de Castro}

To cite this article: Luis S. Villacañas de Castro (2015) “Why Should I Study English If I'm Never Going to Leave This Town?" Developing Alternative Orientations to Culture in the EFL Classroom through CAR, Review of Education, Pedagogy, and Cultural Studies, 37:4, 289-307

To link to this article: http://dx.doi.org/10.1080/10714413.2015.1065616

Published online: 16 Sep 2015.

Submit your article to this journal $₫$

View related articles ¿

View Crossmark data $־$ 


\title{
"Why Should I Study English If I'm Never Going to Leave This Town?" Developing Alternative Orientations to Culture in the EFL Classroom through CAR
}

\author{
Luis S. Villacañas de Castro
}

\section{THE CULTURAL DIMENSION IN FOREIGN LANGUAGE EDUCATION}

This research set out to explore what, on account of my lectures and readings, I interpreted as a pedagogical shortcoming in the intercultural understanding (IU) model of cultural awareness, which prevails in foreign language (FL) education. According to it, fostering intercultural competence (Byram and Gribkova 2002; Deardorff 2009) is often considered one of the most relevant aims of teaching a FL. This perspective originally stemmed from the field of social semiotics, according to which language and culture are inseparable phenomena (Holme 2003), an idea that became translated, in the sphere of FL education, as the need for learners to be educated in the target language culture if knowledge of the language was to occur (Driscoll, Earl, and Cable 2013, 149). Behind this suggestion was - and still is - the belief that language teaching can assume the role of cultural mediation (Borghetti 2013, 255), a thesis that I did not wish to question as much as to analyze from the standpoint of the negative pedagogical consequences which it might easily (and inattentively) lead to.

In both theory and practice, IU provides the dominant approach to the cultural dimension in FL education (Baker 2015) whenever this dimension has been taken seriously. During the last couple of decades, national and international institutions have issued FL educational policies that recommend teachers to include the development of intercultural awareness among the goals of the area, at every educational level. This tendency has been especially intense in European Union institutions, which look at FL education as an effective way to take advantage of the linguistic and cultural diversity of the peoples of its member states, as made patent in the Common European Framework of Reference for Languages (Council of

(C) Luis S. Villacañas de Castro, Universitat de València (Spain) 
Europe 1996, 102-104). In line with its guidelines, national and regional educational policies of the member states have integrated IU in their curricula, and the Valencian region (where this research is set) has proved no exception to this norm. Its FL curriculum for primary education (6 to 12 years old) includes "intercultural awareness" as one of the six features which receives most attention in its wording, since it "contributes to children's knowledge of customs, forms of social relations, traits and peculiarities of the countries where the foreign language is spoken; in a word, lifestyles which are different from their own" (Conselleria d'Educació 2014, 30322).

As soon as one starts to scratch below the surface of the IU model, one realizes that it is not as simple as becoming acquainted with the culture which, related to specific countries and societies, accompanies a FL. In a manual published by the Council of Europe, Byram and Gribkova (2002) already nuance this approach by saying that "the teacher does not need to have experience or be an expert on the [foreign] country. The teacher's task is to help learners ask questions and to interpret answers" (16). Soon after, the same authors make explicit that IU in fact involved "teaching analytical skills which are much less 'perishable' than just facts" (17), hence the need to focus on the skills and attitudes that learners needed to interpret and analyze the cultural variables that, as a rule, impact on communication, to make sense of any given communicative context. These attitudes are what Byram (1989) finds at the base of intercultural competence and called savoir être.

Of course, some degree of factual or content knowledge - savoirs in Byram's words - is also involved in IU. But Byram and Gribkova (2002) warn the reader that this did not involve "primarily knowledge about a specific culture, but rather knowledge about how social groups and identities function and what is involved in intercultural interaction" (12). Much research shows, however, that this crucial distinction has very often been lost in the process of translating IU programmatic principles into real school contexts and classroom practices, on account of the complexity which such translation involves. Borghetti (2013) conceives this complexity as an outcome of the tension between the intercultural and communicative aims of FL teaching, a conflict from which not even Byram's (1989) framework, despite his efforts, is able to completely detach itself. "Most existing models of intercultural competence," Borghetti (2013) says, "do not specify how IC is linked to communicative competence in the foreign language, in part because many of these have arisen from contexts outside of FLT" (256).

Be that as it may, I believe this tension has manifested itself in at least two ways in the field of FL education, each of which implies a different management of the cultural dimension in the classroom. Byram and Gribkova (2002) identify the most common way of confronting the problem: interpreting IU in terms of teaching and learning factual information about the foreign culture, and not a set of analytical skills (as Byram suggests). Furthermore, on most of the occasions in which this solution was adopted, the content introduced tended to be simplified by the teacher and emptied of any critical depth-especially as the students' FL level descended. Among the consequences that derived from this approach was that the educators contributed to widening the gap between the cognitive level which their pupils were able to attain in their native language, 
and the cognitive level of the contents they were exposed to in the FL lessons, normally leading to student boredom and sense of purposelessness. "[Cultural] content," Byram and Gribkova (2002) warn, "was often isolated and simplified, at times even stereotyped and strictly functional, in order to prioritize communicative objectives" (255). Likewise, in their analysis of forty primary schools across England, Driscoll, Earl, and Cable (2013) give concrete evidence of this simplistic interpretation of IU in FL primary classrooms. Only a quarter of the schools they visited and supervised incorporated cultural references into the FL lessons, and those which did, did so mostly as factual knowledge about the foreign countries, like greetings and cultural landmarks such as significant writers, well-known buildings, typical foods, and so on. In addition, this information tended to stress the differences between the foreign and the local cultures, a problem I will later discuss. Furthermore, methodologically speaking, teachers addressed culture in an "ad hoc manner during the lessons" (153-154), because its inclusion did not derive from a careful preplanning, nor did it receive specific attention within curriculum time. Accordingly, student errors and conceptual misconceptions normally ensued, thus undermining the purpose which prioritized content goals (Driscoll, Earl, and Cable 2013, 155). Finally, Baker (2015) also discovers that "cultural and intercultural awareness are more prevalent in pedagogic theory, and to a lesser extent policy, than they are in practice" (130).

The second way in which FL teachers have tended to deal with the tension between the intercultural and communicative objectives of FL has been by considering that the FL culture required no specific mediation, as if it were similar, equivalent, or even superior to the source culture. This approach has been especially apparent when English has been the FL involved and has been associated with subtle forms of neo-imperialism (Pennycook 2007). In these cases, English language teaching abandoned the national-state paradigm, as Risager (2007) suggests, but only to colonize and impose itself upon the rest of the world. Teachers who think of themselves as instructors of English as an international language or a lingua franca, for example, may more easily make the mistake of identifying English with a global, dominant culture, which their students are necessarily part of, acquainted with, or at least desiring to be so (Ives 2006). But the truth is that, despite the latter's international presence, the assumption that all students wish to be familiar with English implies an ideological as much as a pedagogical mistake.

This mistake has been especially apparent in English as a foreign language (EFL) course books. Even native EFL teachers have shown their concern for biased representations of their own home countries. For instance, through a critical analysis that was reliant on the terminology of cultural studies, Gray (2010) demonstrates that many course books presented values that were specific to new capitalism as if they were neutral, natural, and global ones. As a result, the learning of English became arbitrarily linked to worldviews which could not even be considered representative of the average population of Englishspeaking countries, but only of a reduced and privileged elite. Obviously, nonnative EFL teachers have also been very outspoken critics of this misuse of the cultural dimension in EFL education and made themselves heard from their local contexts. Moirano (2012) and Banegas (2010), both from Argentina, stress 
the negative effects of this publishing and teaching practice. Banegas (2010), for instance, persuasively argues that, by suppressing controversial topics such as politics, alcohol, religion, sex, narcotics, poverty, isms, and so on, from their pages, mainstream EFL course books not only tended to portray Englishspeaking societies as if they were ideal and free from the kind of problems EFL students were exposed to, but furthermore made it harder for these students and their teachers to dialogue and interact with the books' content. This was especially inconvenient in EFL secondary education contexts, because teenagers normally prefer to appropriate knowledge through criticism and debate.

It should be added that these course books made no mention whatsoever of the students' local cultures, languages, and societies. As a result, EFL teachers from all over the world end up with books that remain completely external to the English learners' lives and interests - since they describe a foreign reality in romantic and idealized overtones - and which, in addition, afford no critical path for the teacher and students to access their content. In relation to the tension between the intercultural and communicative objectives of FL, it can be concluded that not only do these global course books contradict the concept of IU involving a set of analytical skills (and not simply factual knowledge) but that they also go against the communicative aims of EFL education, precisely by obstructing students' ability to integrate their own lives and culture into the language tasks.

\section{Alternative Orientations to the Cultural Dimension in FL Education}

The common denominator of the two approaches described above is that, while the first one recognizes the foreign character of the cultural content and the second one amalgamates it directly with the learners' lives, neither of them affirm the latter's local culture in the educational process. That FL education should remain so oblivious of the pupils' cultural, linguistic and cognitive background is very surprising, given the fact that the convenience of integrating it has been a recurrent pedagogical recommendation in FL and SL research literature for several decades. Two concrete strategies have been found suitable to this aim: introducing academic content in the language classroom, on the one hand, and using creative tasks for students to speak and write about themselves, on the other. The first one is related with content and language integrated learning (CLIL) approaches, and an example of the second one can be found, among others, in Cummins and Early's (2011) definition of identity texts. These two ways of dealing with culture bear witness to a more sophisticated understanding of the pedagogical role of culture than is traditionally encountered in FL contexts, solely oriented toward the foreign culture. Consistent with these ideas, for example, is Met's (2004) suggestion that planning "for the integration of culture may mean teaching students about the culture of the speakers of the language they are learning as well as that of the students themselves" (166). Likewise, Widdowson (2012) argues that the FL "has to relate to the context of the learners, to the local context of what they know of the language, but also to their attitudes, values, how they see the world-in short, their reality" (12).

This research strove to explore the possibility of strengthening the students' local culture in primary FL education by building on the abilities, culture, and 
knowledge which they brought from home (López-Gopar 2014). Thus, it considered this pedagogical choice as a more important variable for the success of the FL learning process than that of fostering the students' cultural awareness of the foreign culture, as the IU model seemed to suggest. This alternative understanding of the cultural dimension harmonizes well with other approximations to culture which emphasize its "personal side" rather than its elitist or academic side (i.e., privileging culture with a small c over Culture with a capital C [Moirano 2012, 74]); but, at a deeper level, I believe it actually translates a vital and general pedagogical principle into language education, as valid for this field of knowledge as for any other (i.e., the need to take the students' previous knowledge and experiences into account as the stepping stone for any new learning or cognitive development). Constructivist orientations to education emphasize this as their guiding principle, which one can read in the works of Piaget, Dewey, and Vygotsky. In the case of FL education, this constructivist principle necessarily entails having to build on the students' own cultural experiences, forged in their native language. In other words, only if this principle is respected can the FL start to lose its foreign character. This means that, by ignoring this proviso, FL education has actually been going against a basic pedagogical principle (Villacañas de Castro 2013; Cummins et al. 2011), so the fact that it has faced so many difficulties should come as no surprise. Moirano (2012), for example, claims that "only when English is used to express and advocate local culture and values will it truly represent an international language" (75), and this article agrees basically with this statement. The suspicion that, through the dominant IU paradigm, FL approaches to the cultural dimension tended to pass over the students' cultural background and that this omission brought disastrous pedagogical consequences to the FL subject was one of the main motivations that led me to initiate this research.

\section{METHODOLOGY}

The other strong motivation was my desire to narrow the gap separating the university and school educational worlds, and I soon arrived at the conclusion that collaborative action research (CAR) offered the best methodological framework for doing so. As Wang and Zhang (2014) state in a recent article, "there has been a growing concern within the field of education about the division between theory and practice" (225), a concern which has stimulated many kinds of university-school collaborative projects - also action research (AR) ones. Mitchell, Reilly, and Logue (2009), for example, prove that CAR was an ideal tool for school teachers to face the challenge of "determining how teaching and educational research fit together" in school settings (346). And more recently, Katsarou and Tsafos (2014) invite their student teachers (STs) to carry out their own AR projects during their practicum placement, and successfully supervise their progress through a large CAR framework bringing together their different initiatives.

In the case of this CAR project, three different perspectives were taken into account to explore the cultural dimension in EFL education: those of ten 
university STs, who were training to become primary EFL educators; ten inservice EFL primary school teachers who worked in public schools of Valencia; and mine, a university researcher whose investigations and lectures focused on EFL education and literacy, who acted as the organizer of the project. All ten STs were 22 to 28 years old, most of them were born and raised in Valencia, Spain (except for Haurra, who was a French Erasmus student who ended up staying in Spain to end her degree); most of them (as the school teachers and the university researcher himself did) were bilingual Spanish-Catalan speakers, since the Valencian community is a bilingual region; and, finally, all the participants in the research had learnt English as a foreign language. Apart from her native French, Haurra was fluent in Spanish and was learning Catalan rapidly.

Contrary to the partnership that educational AR normally tries to reinforcethe university-researcher and school-teacher axis (Cole and Knowles 1993; Levin and Rock 2003) - the main focus lay this time on the relationship between the university STs and me, the only ones to carry out real research tasks - for reasons that had to do with the specific academic context in which this CAR project was developed. This means that among the goals of the CAR was not the primary EFL teachers' professional development as researchers, but only mine and that of the ten STs. Concerning the latter, they were all teachers-to-be, in the final year of their degree in Primary Education, and they had received a specific training in EFL teaching. While the CAR project lasted, they were all involved in the last and longest internship period of their degree, which was three and a half months long (from February 3, 2014 to May 16, 2014), in different public primary schools of the region. I was their university supervisor during this practicum period, and my guidance was complemented in situ, and in each case, by an experienced EFL teacher working at the host primary school, who spent the whole day with them.

The inclusion of a final practicum report (FPR), which the STs had to complete, had methodological consequences for the development of the CAR project given that, contrary to what is normally the case in these research structures (in which all decisions are exposed to collective negotiation during the process), the compulsory character of this assignment (together with the fact that they had to follow a specific outline to complete it) imposed restrictions on one of the end-products to be expected, which was established beforehand. According to the Faculty's academic guideline for FPRs, the STs had to identify a teaching problem, dilemma, or situation that was open to improvement through their intervention; derive a hypothesis; devise an action plan intended to bring specific changes in the situation; monitor and assess the effectiveness of the measures adopted; discuss once again the hypothesis; and reflect on the whole research cycle.

Because the outline and the nature of the phases in an FPR matched Elliott's (1990) teacher-as-researcher model perfectly, I suggested to the STs that this should be the orientation adopted to facilitate the articulation of research and teaching tasks during their practicum. The key feature of Elliott's model lies in how it considers that "curriculum practices ... constitute the means by which [teachers] generate and test [their] own and each other's theories" (8). Teaching, that is, is not separated from research because it opens itself up to constant interrogation, experimentation, innovation, and curricular decision-making, with a view to making the classes more appealing for the students. According to Noffke (2010), 
this involves "a conscious and contrasting effort to reframe the nature of teaching as in itself a form of research" (9). The original connection between AR and curriculum development is still maintained by McKernan (2008), in whose opinion "curriculum needs to be seen as a continuous educational experience", , "an educational proposal that invites classroom testing.... In order to test his or her curriculum practice, the teacher must adopt a research stance" (6-7).

Taking all this into account, the main motivation of this CAR project could be safely defined as catering to the STs' transition into teachers-as-researchers in the academic context of their placement period and realization of their FPR and helping them do so as they researched the cultural dimension in primary EFL education. Academically speaking, this CAR aimed to provide a methodological safety net for the STs to learn how to articulate the teaching and research skills that they needed to complete their FPR, and thus graduate. But in the long run it anticipated more than that: No less than that this controlled academic experience would show them how to organize and design educational research initiatives that they could implement in the future, when they worked as school teachers, for the whole educational system to benefit from.

\section{Methodological Negotiations}

The choice of whether or not to structure the whole CAR cycle around the cultural dimension was debated during the introductory meeting celebrated on January 28, 2014, five days before the students embarked on their practicum. Our priority was to set in motion an open-ended process, the exact development of which could not be decided in advance, for it would stem from our collective research. The final decision on this issue wasn't made until the second collective meeting, which took place on February 14, 2014 (after their first week at the schools). We articulated our collective discussions around the following list of questions concerning the cultural dimension:

1. How would you describe the primary students' cultural background?

2. Is the EFL lesson more oriented towards the FL culture or towards the students' one? Are they similar, or not?

3. How would you define the cultural background of the school EFL teacher that supervises your placement period? Is it similar to the students' one, or not?

4. What about your own teacher-culture: how would you define it?

5. Do you think you could transfer your own teacher-culture to enrich your EFL teaching? If so, how?

The last question already invited the STs to think about possible topics for their FPRs. It was then decided that, once this last phase started, the students would be able to use their freedom to explore other research questions, and continue to share and discuss their advances in the context of the CAR sessions.

\section{Interviews, Sessions, and Data Collection}

During the four months that the CAR project lasted, I visited the eight primary schools in Valencia where the STs had been placed. They were all public schools 
and in two cases, two STs shared the same institution. There I met the ten primary EFL teachers who acted as school supervisors and conducted semi-structured interviews with them. They had been previously informed, via e-mail, of the CAR project and of our interest in knowing about how they dealt with the cultural dimension in their EFL lessons. The aim of these interviews was to increase the group's knowledge of the treatment given to this variable in real primary schools, and take this description as a point of departure for the STs to improve through their interventions. Of course, the interviews swerved to and from this topic to cover other aspects related to their supervision of the STs' progress.

Concerning the different school backgrounds, it is worth mentioning that, even though all the centers were in the province of Valencia, some were up to sixty kilometers apart, hence set in very different socio-economic contexts. Schools 1, 2, and 5, for example, were urban schools in the capital of the province, of more than 790,000 inhabitants, whereas the rest belonged to smaller neighboring towns, some of which had enjoyed a rural lifestyle until recently. All three urban schools were based in low-medium working class neighborhoods (let me remind the reader that Spain in undergoing a very harsh economic crisis, which has hit hard on public education), and welcomed many children coming from immigrant families. In addition to this, School 2 provided education to children who suffered severe mental and physical impairment. Among the other five schools, it was difficult to find any unifying trait. Not only were there varying rates of immigration and poverty among the students' families, which were contingent on the town and its prevailing economic sector, but some schools were further defined by specific language programs that depended on whether the students' native language was Catalan or Spanish.

Besides these interviews, the CAR project developed through five collective sessions held at the Faculty of Education in which the ten STs and I participated. They lasted two-and-a-half hours on average. Up till the third session, the five research questions presented above encouraged the STs to describe and reflect on their ongoing experience during the practicum in terms of cultural awareness. They described what they saw in school and in the EFL classroom, and pointed out problems and potential solutions to test in their FPRs. Once the STs chose their individual topics for their FPRs, the rest of the meetings became a suitable research framework to supervise their development, precisely by creating a space in which to share, analyze, monitor, and assess their pedagogical choices, thus completing the whole CAR cycle.

The reader will find below a table listing the collective sessions and interviews included in the CAR project, next to the exact dates in which they took place. As a means of gathering data, after each of these events, I wrote a detailed report $(900$ words on average) with the main ideas which had been covered during the session, followed by my own reflections, which I wrote with the intention of re-using them as follow-ups in the next interviews and collective sessions. The findings which the reader can read below show the results of our collective exploration into how the cultural dimension is currently managed in EFL primary education, and how, thanks to the CAR project, the STs came up with alternative ways of understanding it (see Table 1). 
TABLE 1. Collaborative Action Research Interviews and Collective Sessions

\begin{tabular}{|c|c|c|}
\hline Series & Sessions & Time \\
\hline 1 & Collective session: student teacher (ST) and university researcher (UR) & January 28, 2014 \\
\hline 2 & Collective session: ST and UR & February 14 \\
\hline 3 & Interview: UR and school teacher $\mathrm{n}^{\circ} 1$ & February 25 \\
\hline 4 & Interview: UR and school teacher $\mathrm{n}^{\circ} 2$ & March 7 \\
\hline 5 & Collective session: ST and UR & March 7 \\
\hline 6 & Interview: UR and school teacher $\mathrm{n}^{\circ} 3$ & March 12 \\
\hline 7 & Interview: UR and school teacher $\mathrm{n}^{\circ} 4$ & March 12 \\
\hline 8 & Interview: UR and school teacher $\mathrm{n}^{\circ} 5$ & March 13 \\
\hline 9 & Interview: UR and school teacher $n^{\circ} 6$ & March 14 \\
\hline 10 & Collective session: ST and UR & April 4 \\
\hline 11 & Interview: UR and school teacher $n^{\circ} 7$ & April 9 \\
\hline 11 & Interview: UR and school teacher $\mathrm{n}^{\circ} 8$ & May 15 \\
\hline 12 & Collective session: ST and UR & May 16 \\
\hline
\end{tabular}

\section{CAR FINDINGS}

\section{Teachers' Interviews}

As was expected, during the interviews all the EFL teachers said that culture was a dimension that they took into account in their lessons, so they all showed some degree of cultural awareness. This level varied among them, of course, as did the ideas and practices into which it translated. None of them had received specific training on the different ways of integrating culture, nor did they reveal a systematic perspective on how this integration should take place. Thus, it became obvious to me that the theory that grounded their practice remained implicit, and was based - so it seemed - on intuitive notions. Probably on account of the nonconceptual nature of their arguments, the teachers felt more comfortable when they described concrete anecdotes rather than discussing theoretical frameworks or principles. At any rate, the examples through which they described their approach to the cultural dimension were clearly oriented toward the foreign culture, not the students' one. In fact, the teacher from School 4 was the only one to design tasks that also attended to the students' local culture and experiences, as the reader will have the chance to see. This means that the prevailing interpretation of the cultural component among these primary EFL teachers coincided largely with the tendency established by the IU, though maybe it would be more exact to say that it coincided largely with the distorted version of the IU model that, as mentioned above, focused on the foreign culture by introducing factual information. In fact, the interviews revealed that the teachers neither discriminated between savoir and savoir être nor devoted specific attention to each of them; it seemed as if they expected that the sole exposition to foreign cultural references would lead, by itself, to the development of intercultural attitudes and skills in their pupils.

As in Driscoll, Earl, and Cable (2012), it soon became clear to me that songs and celebrations from English-speaking countries were the most common cultural references. Nearly all the teachers said that their syllabus echoed 
celebrations such as St. Valentines' day, Halloween, and even St. Patrick's. Their lessons included information about the origins of these festivities and also practical workshops through which the pupils disguised themselves in customary dresses, wrote friendly letters in English to each other, and so on. Sometimes the whole school took part in these festivals (only then was English heard outside the EFL classroom walls), as when the students sang English Christmas carols together with Catalan or Spanish ones, or when schools designed projects whereby pupils dealt with different special days of the year in a different one of the three languages, according to the nature of the commemoration. School 4, for instance, used Catalan to celebrate a regional festival, Spanish to commemorate Human Rights Day, and English to honor International Peace Day. On these occasions, values such as tolerance and respect (so related to the analytical skills and attitudes pursued by the IU model) were decisively taught together with content that was related to both the FL and local culture-for example, by contrasting different kinds of festivities. Only then were savoir être and savoirs well combined in the FL classroom. The teachers mentioned that these activities were exceptional, so during most of the school year they added no extra cultural content to the one included in the course book.

This last observation paves the way for this article to explore some of the negative effects that seemed to derive from the cultural orientation generally displayed by these EFL teachers. They confirmed my initial hypothesis that the IU model of cultural awareness for FL education could easily lead to some important pedagogical shortcomings. These never appeared as evident to me as when I listened to the EFL teacher in School 7 relate the following anecdote. She was a young woman, who liked to travel a lot around the world and presented her students with objects she bought during her travels; the message she wanted to convey to her pupils was that it was easy to meet interesting people, societies, and cultures from all over the world if one learnt English. Through this, she intended to raise the students' interest in the foreign world waiting beyond the town's walls, and expected this enthusiasm to transfer to the EFL classes. And sometimes this strategy worked, especially with those students whose families could afford to pay for private language academies or, even better, to send them on summer courses in English-speaking countries. As for the rest of the students, they frequently asked their teacher the following question: "But then, why should I study English, if I am never going to leave this town?"

This was not the first time I had come across this anecdote during this CAR project. In fact, the FL teacher from School 2 had been interrogated in a similar manner by a student's father who declared never to have left Valencia or its environs and expected that the same would occur with his son. Likewise, a ST had also reported a similar reaction coming from one of her pupils in School 6, so the CAR group had the opportunity to discuss this reaction in one of the collective sessions. It is interesting to note that such comments (and the attitudes they represented) normally arose among working-class families, especially among those characterized by a low socioeconomic status (SES), a condition that, as a result of the economic crisis, has spread a lot among the population in Spain. Social class, that is, had a strong impact on EFL learning (López-Gopar and Sughrua 2014) especially regarding variables such as purpose and motivation. 
Conversely, comments like those just mentioned brought to the fore a major albeit latent concern for most EFL educators, namely how to justify learning a foreign language in terms that were significant and meaningful to its learners. We also had the chance to discuss this topic in one of the collective sessions. Those comments also emphasized the role which the cultural dimension played in this matter, because they suggested that low SES students (hence those more likely to profit from a public system of education) remained immune to the international or transnational lure typically associated with EFL education, one that presents it as a mediating and unifying force between peoples and cultures, or by identifying it with the values of globalization and new capitalism (Gray 2010). As a reaction to the myth which the FL teacher from School 7 helped to reinforce, precisely by staging herself as an individual who, thanks to English, was able to live and work all over the world, some students and their families continued to affirm the values of their local, immediate realities, where their relatives and friends lived. Consequently, against the grain of political and linguistic authorities, it became clear from the interviews that FL teachers should better find different arguments to justify EFL education to their pupils. Giving a different orientation to the EFL cultural component could play an important role in this regard.

Far from judging or criticizing these student attitudes, this CAR considered them as evidence of the lack of importance traditionally conceded to EFL education by many Spanish families on account of socioeconomic and cultural inertias, which the present economic crisis has intensified. But the CAR also saw these comments as an opportunity to reflect on the pedagogical demands, incumbent on teachers, which derived from this situation. For example, the EFL teacher from School 2 reported that whenever a family did not have enough money to buy all the school course books their children needed, the EFL course book was always the one they left out. Likewise, among many immigrant families, the EFL subject was not considered important because the family priority lay in the two official languages spoken in the region, Spanish and Catalan, which some immigrant parents did not master yet (as related by the teacher in School 8). Finally, many parents (and not necessarily low SES ones) could neither help nor contribute to the children's EFL learning in so far as they had never received any English education themselves, on account of the fact that French had been the foreign language traditionally taught in Spain, and the first generations of parents to receive EFL education were starting, just now, to send their children to school (Schools 1, 2, 6, and 7).

Although all the teachers interviewed alluded to most of these factors, and identified them as obstacles that came in the way of their targeted learning and teaching goals, curiously most of them failed to appreciate how they could improve this situation, or how a different approach to the cultural dimension in class could be helpful for this purpose. If many low SES students reacted negatively to an orientation that emphasized foreign aspects (even more so when this orientation implied the acquisition of factual knowledge), then what was needed was for the EFL teachers to operate a sharp turn in their lessons, and open them up to the students' original culture, to their specific interests and life experiences. In contrast to what the energetic teacher from School 7 believed, the pupils who 
reacted positively to her spontaneous representation of English as an international language, and to the advantages associated with it, did not do so because of the intrinsic attractiveness of this foreign culture, but because those students could already relate to it: They attended private language classes and traveled in the summer to English-speaking countries. It was therefore not the novel and foreign character of English language and culture that appealed to them, but the fact that it already formed part of their lives and learner identities.

Only the EFL teacher from School 4 showed an alternative pedagogical approach to culture, more in keeping with the hypothesis of this CAR. Her way of dealing with it gave priority to the pedagogical preconditions for successful learning over the specific intercultural goals of the IU model. As has already been said, her school organized the academic course through projects and workshops centered on significant dates in the calendar and the use of different languages for different dates. In the context of these activities, this EFL teacher designed a series of activities for primary students of all ages around International Women's Day, the final outcome of which consisted of each student writing a short biographical text, in English, on a woman who played or had played a significant role in society. The pupils were free to decide which woman to choose, based on their interests, and in the end women from all walks of life were represented. But more important than this final biographical text was the way in which the whole workshop was organized, because the teacher planned activities through which her pupils extended their immediate life experiences and transferred the emotional and cultural meaningfulness attached to them to their work with the FL. She started by asking her pupils to bring photos of any female member in their family (mother, grandmother, etc.) and to write a short descriptive paragraph about her. Poems were then composed for Mother's Day, and only after this did the group start to research the lives of significant women through proper academic work. All the work was finally brought together on posters, which were hung from the walls for all the school to read (see Figure 1).

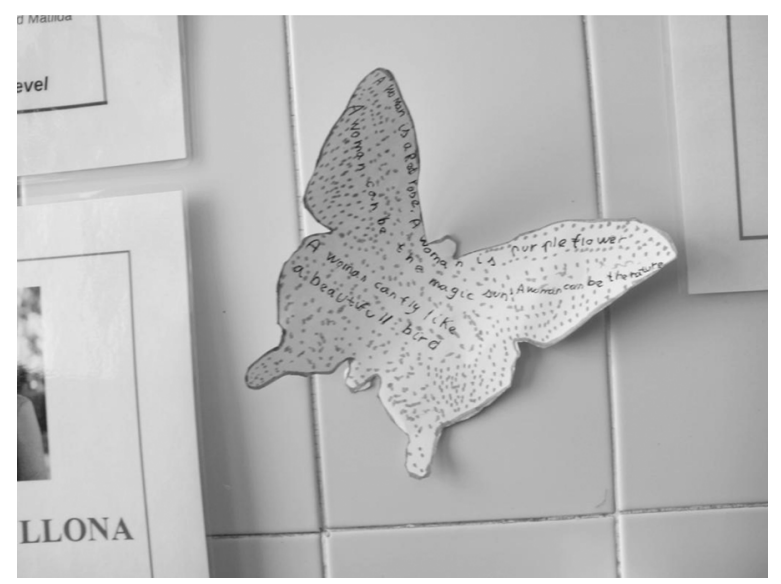

Figure 1. Mother's day poem on school wall. 


\section{Student Teachers' Development}

In the very first CAR session, it became clear to me that the STs would have to overcome their spontaneous notions of the cultural dimension (which they identified too closely with national or ethnic realities) before they could move on to more innovative approaches and coherent pedagogical practices than those put forward by most of their school supervisors, as described above. "If primary students barely know any English, how can we expect them to learn English culture?" was the group's first reaction. Critical in this regard was the distinction between home culture vs. school culture, discussed during the first two CAR sessions. By reflecting on their class experiences in the light of this dichotomy, the STs comprehended that the normal distance between these two concepts became wider in the EFL subject, due to the different language involved. Hence the imperative need to find even more effective ways to bridge this gap by intervening pedagogically on the cultural plane. In line with this aim, two STs, Haurra and Carles, came up with original and sophisticated activities for their FPRs, which drew directly on this CAR topic. They experimented with the cultural dimension in EFL education by applying an orientation that, instead of focusing on the English culture, gave priority to building on the pupils' home and family culture.

Let me briefly describe these two workshops and provide some illustrations (though privacy clauses prevent me from showing images of the children involved). These two workshops bore witness to the most remarkable cases of ST development attained through this CAR since, through them, the two STs fulfilled all the aims which I had hoped for in advance.

Possibly on account of her own foreign origin, Haurra showed a keen understanding of the pedagogical need for teachers to organize adequate cultural transitions in their language classes. Her workshop was called "My Way to School," and it was implemented with students aged eight and nine, in School 1. The pupils drew a simplified map of the itinerary that they followed daily from home to school. First, by adopting the kind of bird's-eye view found in the GoogleMaps application (which Haurra accessed through the class computer to show her pupils how their home to school journeys showed on a map), the children had to divide a large piece of card into several streets and blocks of buildings and include inside them some of the institutions they came across each morning, as their parents or other family members accompanied them to school, on foot or by car. Once the maps were completed, and their routes drawn on top, the children had to describe their route in a written form. This meant they had to make use of terms that signaled direction ("I turn left, I turn right, I walk ahead..."), and vocabulary related with the buildings, institutions, and spaces they came across. But they did so with a clear communicative purpose in mind: Namely, to refer to their immediate surroundings and to an essential activity which they carried out daily. Furthermore, it was through this activity that their school and home environments met. Indeed, as the reader may have guessed, Haurra's workshop did not only address her students' lives and academic needs, but it was itself a metaphor of our CAR topic: It symbolized and articulated her students' transition between two different cultural and linguistic realities (home 


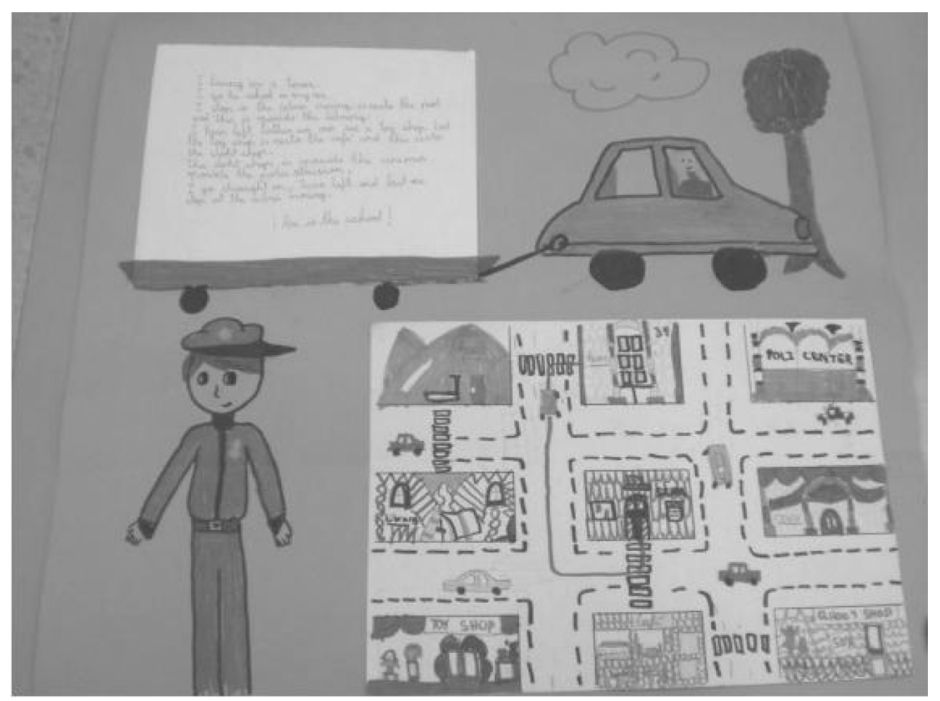

Figure 2. My way to school.

and school, the latter being the only place where they were exposed to a foreign language). This transition was a pedagogical one, but also a spatial one which could be traced upon a map. The pedagogical argument behind it became evident in the methodology of the workshop (see Figure 2).

In the same manner, Carles' original idea for his FPR arose in the process of responding to the fourth and fifth questions which were presented to the CAR group: "How would you define your own teacher culture?" and "Do you think you could transfer your own teacher-culture to your own EFL teaching? If so, how?" Actually, it so happened that, before studying for a degree in Primary Education, Carles had already completed one in audiovisual communication. Inspired by these two questions, he devised a workshop — "This Is My Town! Critical Thinking in the EFL Classroom!"-for a group of eleven- and twelveyear-old students from School 6, whom he was spending his placement with. "The aim of this project," Carles writes in his FPR, "is for the pupils to use the English language to speak about their town. By recording short video documentary pieces, they will use the English language as a vehicle to express their own vision of their environment." This allows Carles not only to give a local turn to the cultural orientation of the EFL subject, but also to enrich the lessons and the pupils' audiovisual knowledge through his own expertise that he teaches in English. To provide a well-founded pedagogical framework to the whole workshop, Carles drew on CLIL and action-based approaches to FL education, and even introduced a critical edge by making the pupils reflect and evaluate the geographic and social transformation which their town had undergone in the last couple of decades, through dialogues in class. The workshop included the following sequence of activities: First, the students brought to class photos of their favorite places in town (the sports center, the cultural center, the park, the church, the main square, etc.); then, they described each of them and justified 


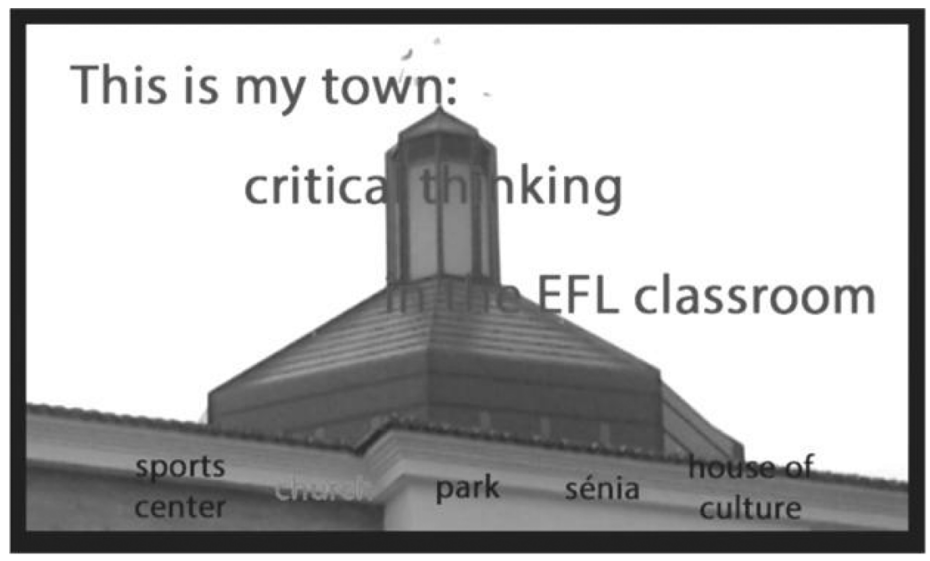

Figure 3. This is my town! DVD menu.

their choice in front of their peers; after this, they researched collectively on the history of those places, by searching in the town library or asking older relatives; and finally they selected and wrote down this information in the form of a suitable script. At the end, the videos were shot on site during class hours, uploaded and organized into a DVD (Figure 3), and the whole group watched them in class and commented on the results, focusing on content as much as on language form.

Despite the fact that the aim of this article is not to evaluate the success of these workshops but rather to assess them as evidence of the ST's development, the results were positive in terms of the learners' interest and engagement in the workshops. These two FPRs were immediately related with the CAR topic, whereas the other STs preferred to draw on the pedagogical knowledge produced during the collective sessions (and during their own placement) to apply it to topics such as the use of games in EFL education, creative teaching and creative learning, the use of poetry, storytelling and children's literature, the creation of learning communities, and the CLIL approach. All in all, the basic conclusion that the STs reached through the CAR and displayed in their FPRs consisted of two interconnected ideas: the need to link EFL education to students' culture (conceived broadly as their local experiences and interests), and the understanding that this would only occur through student-oriented pedagogies, that is, provided that the teacher handed the initiative to the primary students through workshops that gave them the chance to speak and write about themselves and what they knew. The STs' development in relation to the CAR topic was hence accompanied by the parallel development of their pedagogical awareness.

Of course, not all the STs showed the same degree of progress, and the diversity of FPR topics made it harder to appreciate the general level of development that the sessions seemed to show. But toward the end of the CAR project a conceptual breakthrough had clearly taken place, one which contrasted heavily with the very first session when some STs had voiced their skepticism toward the feasibility of primary students actually speaking about themselves in English, 
due to their low FL level. The STs who initially expressed these doubts justified the teacher-oriented pedagogy that primary teachers usually used in their FL lessons, by rigidly focusing on the course books and their de-contextualized exercises. Like the teachers from Schools 2 and 6 did in their interviews, these STs seemed to defend the existence of a threshold level below which it seemed unrealistic for teachers to tap into cultural aspects in the EFL class. Luckily, this perspective changed as the CAR developed. Independently of the specific topics developed in the FPRs, and also of the approaches or resources they used, all of them showed a practical level of understanding about the need to appeal to the students' local culture (and the wealth it incorporated) as the best way to sustain them through the hardships involved in learning a FL. In other words, the communicative aims of EFL education had to be designed first in relation to the students' culture, and not the foreign one. The moment they realized this, the STs understood why the following series of coincidences, which shaped the present situation of EFL education in primary levels, were not a matter of chance (yet at the same time knew how to overturn them): teachers' total dependency on course book material, lack of students' active learning, and a cultural orientation to EFL education premised on a simplistic reading of the IU model that tended to favor aspects of the foreign culture over the students' one, and which made no effort to connect them.

This situation probably reached its most radical manifestation in a case that another ST, Araceli, narrates in her FPR. I wish to end this section with this example, because it bears witness to a further case of ST development, immediately related with the CAR topic and goals. Araceli was carrying out her internship in School 2, which-as said above-provided education to children who suffered from severe mental and physical impairment. One of her obligations there was to support an eight-year-old girl with high cerebral damage, and who needed the use of a wheelchair. "That first day", Araceli recalled,

the teacher told me to help this girl complete a fill-in-the-gaps exercise from the EFL course book. I started reading the exercise, but I stopped quickly once I realized what she was being asked to do. The exercise was next to the picture of a dancer, so the pupil had to add the modal verb in the sentence, as in "I can dance." I kept reading the task and discovered that all the sentences were similar: "I can run," "I can ride a bike" ... but not "I can read" or "I can dream."... How could the EFL teacher not modify that exercise? Sentences like "I can run" or "I can dance" may be useful for explaining modal verbs; but teachers have to teach within a context, always linking the subject matter to the pupils' reality. And that day, what the course book said was far from reality.

The pedagogical contradictions of EFL education don't usually reach this level of intensity and dramatic quality, yet the findings from this CAR project suggest that, theoretically speaking, this example is not qualitatively different from the way the cultural dimension was generally tackled in Primary FL education, that is, by making students become acquainted with a cultural reality that was - and in many cases, would remain in the future - as distanced from their own as the foreign language they were striving to learn. From this contradictory educational 
experience, no learning could possibly ensue. As an alternative, the STs involved in this CAR project gave their pupils the chance to actually speak and write about themselves in English, hence to undergo a meaningful and worthwhile educational experience in relation to EFL education. The quality of these school experiences should provide the main justification for the students' effort to learn a foreign language, not their ability to speak and work, in an indeterminate future, with foreign citizens in foreign countries.

\section{CONCLUSION}

By uniting school and university realities, this CAR project succeeded in fulfilling the two main objectives that it originally set out to attain. First and most important, the STs who took part in it were able to develop and apply their nascent research skills in a real educational context (their school internship) and did so in line with the teacher-as-researcher model, which also afforded a convenient methodology for the STs to satisfy their academic needs. The fulfillment of this first aim progressed in parallel with the satisfaction of the second one, since the different phases of the CAR research cycle allowed the STs to critically discuss, analyze, and experiment with the cultural variable in primary EFL education. As a result of our disciplined inquiry organized around five key questions, the STs' perspective widened (as did mine), especially as the collective discussions started to unearth the pedagogical underpinnings of the cultural dimension. By the end of the process, the STs had unquestionably become better teachers and researchers, and furthermore more able to articulate both dimensions. Not only were they more aware of the potential of the cultural dimension to improve the quality of the EFL learners' educational experience, when their own cultural and experiential background became imbedded into the communicative aims of the subject; but also more prepared to continue improving their own theoretical and practical understanding of the cultural dimension in EFL education through constant research into their own teaching.

Finally, even as this CAR project addressed the specific characteristics of the local educational context which it set out to transform (one in which English was the FL taught at school), both the concerns that set the investigation in motion and the culturally-responsive pedagogical solutions that were adopted in the process are likely to be transferable to other FL educational contexts where English is not the foreign language involved. As has been demonstrated, the need to build on the students' native language and culture is a pedagogical precondition that should be respected even when teaching a foreign language is the primary goal.

\section{FUNDING}

This article is framed within the research project GV/2015/050, funded by the Conselleria d'Educació, Cultura i Esports of the Generalitat Valenciana (Spain). 


\section{REFERENCES}

Baker, W. (2015). Research into Practice: Cultural and Intercultural Awareness. Language Teaching, 48(1), 130-41. doi:10.1017/s0261444814000287

Banegas, D. L. (2010). Teaching More than English in Secondary Education. ELT Journal, 65, 80-82. doi:10.1093/elt/ccq016

Borghetti, C. (2013). Integrating Intercultural and Communicative Objectives in the Foreign Language Class: A Proposal for the Integration of Two Models. The Language Learning Journal, 41, 254-267. doi:10.1080/09571736.2013.836344

Byram, M. (1989). Cultural Studies in Foreign Language Education. Clevedon, UK: Multilingual Matters.

Byram, M. and Gribkova, B. (2002). Developing the Intercultural Dimension in Language Teaching: A Practical Guide for Teachers. Strasbourg, France: Council of Europe.

Cole, A. L. and Knowles, J. G. (1993). Teacher Development Partnership Research: A Focus on Models and Issues. American Educational Research Journal, 30, 473-495. doi:10.3102/ 00028312030003473

Conselleria d'Educació. (2014). DECRETO 7311, de 7 de julio, del Consell, por el que se establece el currículo de la Educación Primaria en la Comunitat Valenciana. València, Spain: Diari oficial de la Comunitat Valenciana.

Council of Europe. (1996). Common European Framework of Reference for Languages: Learning, Teaching, Assessment. Strasbourg, France: Language Policy Unit.

Cummins, J. and Early, M. (2011). Introduction. In J. Cummins and M. Early (Eds.), Identity Texts: The Collaborative Creation of Power in Multilingual Schools (pp. 3-19). London, England: Trentham/Institute of Education Press.

Cummins, J., Early, M., Leoni, L., and Stille, S. (2011). It Really Comes Down to the Teachers, I Think': Pedagogies of Choice in Multilingual Classrooms. In J. Cummins \& M. Early (Eds.), Identity Texts: The Collaborative Creation of Power in Multilingual Schools (pp. 153-163). London, England: Trentham/Institute of Education Press.

Deardorff, D. (2009). Synthesizing Conceptualizations of Intercultural Competence: A Summary and Emerging Themes. In D. Deardorff (Ed.), The SAGE Handbook of Intercultural Competence (pp. 264-270). Thousand Oaks, CA: Sage.

Driscoll, P., Earl, J., and Cable, C. (2013). The Role and Nature of the Cultural Dimension in Primary Modern Languages. Language, Culture and Curriculum, 26(2), 146-160. doi:10.1080/07908318. 2013.799675

Elliott, J. (1990). Action Research for Educational Change. Milton Keynes, UK: Open University Press.

Gray, J. (2010). The Branding of English and the Culture of the New Capitalism: Representations of the World of Work in English Language Textbooks. Applied Linguistics, 31, 714-733. doi:10.1093/ applin/amq034

Holme, R. (2003). Carrying a Baby in the Back: Teaching with an Awareness of the Cultural Construction of Language. In M. Byram and P. Grundy (Eds.), Context and Culture in Language Teaching and Learning (pp. 18-31). Clavedon, UK: Multilingual Matters.

Ives, P. (2006). "Global English": Linguistic Imperialism or Practical Lingua Franca? Studies in Language and Capitalism, 1, 121-141.

Katsarou, E. and Tsafos, V. (2014). Student-Teachers as Researchers: Towards a Professional Development Orientation in Teacher Education. Possibilities and Limitations in the Greek University. Educational Action Research, 21, 532-548. doi:10.1080/09650792.2013.851611

Levin, B. B. and Rock, T. C. (2003). The Effects of Collaborative Action Research on Preservice and Experienced Teacher Partners in Professional Development Schools. Journal of Teacher Education, 54(2), 135-149. doi:10.1177/0022487102250287

López-Gopar, M. E. (2014). Teaching English Critically to Mexican Children. ELT Journal, 68, 310-320. doi:10.1093/elt/ccu017

López-Gopar, M. E. and Sughrua, W. (2014). Social Class in English Language Education in Oaxaca, Mexico. Journal of Language, Identity, and Education, 13, 104-110. doi:10.1080/15348458. 2014.901822

McKernan, J. (2008). Curriculum and Imagination: Process Theory, Pedagogy and Action Research. London, England: Routledge. 
Met, M. (2004). Teaching Content Through a Second Language. In F. Genesse (Ed.), Educating Second Language Children. The Whole Child, the Whole Curriculum, the Whole Community (11th ed., pp. 159-182). Cambridge, UK: Cambridge University Press.

Mitchell, S. N., Reilly, R. C., and Logue, M. E. (2009). Benefits of Collaborative Action Research for the Beginning Teacher. Teaching and Teacher Education, 25, 344-349. doi:10.1016/j.tate.2008.06.008

Moirano, M. C. (2012). Teaching the Students and Not the Book: Addressing the Problem of Culture Teaching in EFL in Argentina. Gist Education and Learning Research Journal, 6, 71-96.

Noffke, S. E. (2010). Revisiting the Professional, Personal, and Political Dimensions of Action Research. In E. Noffke \& B. Somekh (Eds.), The SAGE Handbook of Educational Action Research (pp. 6-24). Los Angeles, CA: Sage.

Pennycook, A. (2007). ELT and Colonialism. In J. Cummins \& C. Davison (Eds.), International Handbook of English Language Teaching (pp. 13-24). New York: Springer.

Risager, K. (2007). Language and Culture Pedagogy: From a National to a Transnational Paradigm. Clevedon, UK: Multilingual Matters.

Villacañas de Castro, L. S. (2013). Teaching English as a Foreign Language in Accordance with SocialConstructivist Pedagogies. Tejuelo: Revista de Didáctica de la Lengua y la Literatura, 17, 97-119.

Wang, Q. and Zhang, H. (2014). "Promoting Teacher Autonomy Through Universityschool Collaborative Action Research. Language Teaching Research, 18, 222-241. doi:10.1177/ 1362168813505942

Widdowson, H. G. (2012). Closing the Gap, Changing the Subject. In J. Hüttner, B. MehlmauerLarcher, S. Reichl, and B. Schiftner (Eds.), Theory and Practice in EFL Teacher Education, edited by (pp. 3-15). Bristol, UK: Multilingual Matters. 